Expressi on, pur i fi cat i on and ant i geni ci ty of Neospor a cani num ant i gens usi ng si I kworm I arvae targeting for subunit vaccines

\begin{tabular}{|l|l|}
\hline 著者 & $\begin{array}{l}\text { Ot suki Takahi ro, Dong Ji nhua, Kat o Tat suya, } \\
\text { Park Enoch Y. }\end{array}$ \\
\hline $\begin{array}{l}\text { j our nal or } \\
\text { publ i cat i on ti t l e }\end{array}$ & Vet er i nar y Par asi tol ogy \\
\hline vol une & 192 \\
\hline number & $1-3$ \\
\hline page r ange & 284287 \\
\hline year & 2013 02-18 \\
\hline 出版者 & El sevi er \\
\hline 権利 & $\begin{array}{l}\text { Copyr i ght } \\
\text { reser ved. }\end{array}$ \\
\hline URL & ht t p: //hdl . handl e. net /10297/6936 \\
\hline
\end{tabular}




\section{Expression, purification and antigenicity of Neospora \\ 2 caninum-antigens using silkworm larvae targeting for \\ 3 subunit vaccines}

4 Takahiro Otsuki ${ }^{\text {a }}$, Jinhua Dong ${ }^{\text {a }}$, Tatsuya Kato ${ }^{a}$ and Enoch Y. Park ${ }^{\text {a,b,* }}$

$5 \quad$ a Laboratory of Biotechnology, Department of Applied Biological Chemistry, Faculty of

6 Agriculture, Shizuoka University, Shizuoka 422-8529, Japan

$7 \quad{ }^{\mathrm{b}}$ Laboratory of Biotechnology, Integrated Bioscience Section, Graduate School of

8 Science and Technology, Shizuoka University, 836 Ohya, Suruga-Ku, Shizuoka

9 422-8259, Japan

\footnotetext{
* Corresponding author at: Integrated Bioscience Section, Graduate School of Science and Technology, Shizuoka University, 836 Ohya, Suruga-Ku, Shizuoka 422-8259, Japan. Tel. \& Fax: +81-54-238-4887.

E-mail address: acypark@ipc.shizuoka.ac.jp (E.Y. Park).
} 
11 Infection of Neospora caninum causes abortion in cattle, which has a serious worldwide impact on the economic performance of the dairy and beef industries. Now,

13 inexpensive and efficacious vaccines are required to protect cattle from neosporosis in

14 livestock industry. In this study, N. caninum surface antigen 1 (SAG1) and SAG1-related sequence 2 (SRS2) were expressed in hemolymph of silkworm larvae as a soluble form. Expressed SAG1 and SRS2 clearly showed antigenicity against $N$. caninum-positive sera of cow. SAG1 and SRS2 were purified to near homogeneity from hemolymph of silkworm larvae using anti-FLAG M2 antibody agarose: approximately $1.7 \mathrm{mg}$ of SAG1 from 10 silkworm larvae and $370 \mu \mathrm{g}$ of SRS2 from 17 silkworm larvae. Mice that were injected by antigens induced antibodies against SAG1 and SRS2. This study indicates that it is possible that this silkworm expression system leads to a large-scale production of $N$. caninum-antigens with biological function and low production cost. Bombyx mori nucleopolyhedrovirus (BmNPV) bacmid expression system paves the way to produce largely and rapidly these recombinant antigens for its application to subunit vaccines against neosporosis in cattle. 


\section{Introduction}

Neospora caninum is a protozoan parasite of animals, which causes reproductive failure in cattle (Dubey et al., 2007). Neosporosis is a major cause of abortion in cattle and has serious impacts on the economic performance of dairy and beef industries (Reichel and Ellis, 2006). Vaccination is the most cost-effective way to control neosporosis, according to an economic analysis (Reichel and Ellis, 2006).

Subunit vaccines have been the most focused in this field. Various $N$.

caninum-antigens have been reported and evaluated as a vaccine. $N$. caninum surface antigen 1 (SAG1), anchored on the surface of tachyzoites by glycosylphosphatidylinositol (GPI) anchor, was expressed in E. coli and purified recombinant SAG1 protected cerebral infection of $N$. caninum when immunized into mice (Cannas et al., 2003). SAG-related sequence protein 2 (SRS2) has also GPI anchor (Nishikawa et al., 2002), being localized on the surface of $N$. caninum, and is expressed in both tachyzoites and bradyzoites (Fuchs et al., 1998; Hemphill and Gottstein, 1996). Antibodies against SRS2 inhibit tachyzoite from attaching and invading to host cells and induce cellular and humoral immunity, supposing that SRS2 is a strong vaccine candidate (Baszler et al., 2008; Haldorson et al., 2006; Nishikawa et al., 2000).

Silkworms have been used for recombinant protein production because of its high capacity of producing proteins and cost-effectiveness for large-scale production (Kato et al., 2010(Li et al., 2010; Tsuji et al., 2011; Usami et al., 2010; Zhou et al., 2011). 
Veterinary vaccines produced by recombinant baculoviruses are now on the market and some are under the development for licensing (Kamen et al., 2011). In addition, subunit vaccines produced in silkworms are immunogenic and efficacious in cattle when used as prophylactic ones (Li et al., 2008; Li et al., 2011). Especially, in these cases, a hemolymph of silkworm larvae containing expressed the recombinant protein was used as a subunit vaccine against infectious disease in cattle.

In this study, several antigens of $N$. caninum were expressed as FLAG-tagged proteins in silkworm larvae using BmNPV bacmid system. Purified antigens with an adjuvant induced antigen-specific antibodies in mice. This study demonstrates that BmNPV bacmid system can be applied to cost-effective large-scale production of subunit vaccines against cattle.

\section{Materials and methods}

\subsection{Gene amplification, cloning, and construction of recombinant BmNPV bacmids}

SAG1 or SRS2 was expressed in hemolymph of silkworm larvae using the signal peptide sequence of bombyxin from Bombyx mori (bx signal). bx signal peptide allows expressed proteins to be secreted into hemolymph of silkworm larvae efficiently (Park et al., 2007). Genomic DNA of $N$. caninum Nc-1 was purchased from American Type Culture Collection (ATCC No. 50843D) and used as a PCR template. Antigen genes, sag1 and srs2 have no intron in genomic DNA. Then sag1 gene was amplified by PCR using SAG1-F (TATGGTACCGATCAGAAAAATCACCTCTA) and SAG1-R 
(ATAGAGCTCTCACGCGACGCCAGCCGCTAT). srs2 gene was amplified by PCR using SRS2-FL-F (TGCGGTACCGATTTCCTCGGGCAGTGAGAC) and SRS2-FL-R (ATAGAGCTCTCACGCGACGCCAGCCGCTAT). Each gene was cloned into

pET52b vector at Kpn I-Sac I site. Next, each gene was amplified by PCR using

CACC-bx-FLAG-HRV3C primer

\section{(CACCATGAAGATACTCCTTGCTATTGCATTAATGTTGTCAACAGTAATGTGG} GTGTCAACAGACTACAAGGATGACGATGACAAGGGTGCACTTGAAGTCCTC

TTTCAG) and each reverse primer (SAG1-R or SRS2-FL-R). Each amplified gene was composed of bx signal peptide sequence, FLAG peptide sequence, human rhinovirus $3 \mathrm{C}$ protease cleavage site sequence, and each protein coding sequence. Each amplified gene was inserted into pENTR/D/TOPO (Life Technol. Japan Ltd, Tokyo, Japan) vector by TOPO reaction. A recombinant $\mathrm{CP}^{-} \mathrm{Chi}^{-} \mathrm{BmNPV}$ bacmid harboring each gene (BmNPV CP${ }^{-} \mathrm{Chi}^{-}-\mathrm{bx}-\mathrm{FLAGHRV3C-SAG1s}$ or BmNPV CP${ }^{-}$ Chi-bx-FLAGHRV3C-SRS2FL) was constructed to express each N. caninum-antigen according to the previous report (Park et al., 2008).

2.2. Injection of BmNPV bacmid DNA into silkworm larvae, harvesting hemolymph of silkworm larvae, and purification of expressed recombinant N. caninum-antigens

BmNPV bacmid DNA injection into silkworm larvae and breeding silkworm larvae were performed according to the previous report (Park et al., 2008). Hemolymph was collected from silkworm larvae by cutting prolegs, and 1-phenyl-2-thiourea was put 
into collected hemolymph at $0.1 \mathrm{mM}$ to prevent melanization. Hemolymph was

centrifuged at $10000 \times \mathrm{g}$ for $15 \mathrm{~min}$ to remove hemocytes and debris, and its supernatant was used as a hemolymph sample.

To purify expressed recombinant $N$. caninum-antigens, $2 \mathrm{ml}$ of anti-FLAG M2 antibody agarose (Sigma Aldrich Japan, Tokyo, Japan) was packed in an empty column and equilibrated with TBS (pH 7.5). Hemolymph diluted 5-fold with TBS was loaded onto the anti-FLAG M2 antibody agarose column. The column was washed with $40 \mathrm{ml}$ of TBS after loading hemolymph, and proteins were eluted with $8 \mathrm{ml}$ of glycine- $\mathrm{HCl}$ buffer (pH 3.5). Every fraction of $1 \mathrm{ml}$ elute was collected.

\subsection{SDS-PAGE, western blot and protein concentration determination}

SDS-PAGE and western blot were carried out according to the previous report (Tsuji et al., 2011). Mouse anti-FLAG M2 antibody (Sigma Aldrich Japan) and goat anti-mouse labeled with horseradish peroxidase (HRP) (GE Healthcare Japan, Tokyo, Japan) were used as primary and secondary antibodies. Protein concentration was determined by BCA protein assay kit (Thermo SCIENTIFIC, Rockford, IL, USA).

\subsection{Indirect enzyme-linked immunosorbent assay (Indirect ELISA)}

One hundred microliters of hemolymph or purified antigens were immobilized on an ELISA plate at $4{ }^{\circ} \mathrm{C}$ overnight. Solution in each well was removed, and $2 \%$ skim milk in PBST (PBS containing $0.05 \%$ Tween 20 ) as a blocking buffer was added into each well at room temperature for 2 hours for a blocking step, followed by collection 
of their serum samples and washing each well using a plate washer (MODEL1575

111 ImmunoWash, Bio-Rad) with PBST. Then, $100 \mu$ of Neospora-positive bovine serum

112 (gifted by Mr. Junichi Noda of Shizuoka Prefecture Tobu Livestock Disease

113 Diagnostic Center) diluted with 1000-fold with PBST was added to each well, and then,

114 the ELISA plate was incubated at room temperature for an hour. Each well was washed using a plate washer with PBST, and $100 \mu$ l of goat anti-bovine IgG antibody-conjugated HRP (Jackson ImmunoResearch Lab. Inc.) was added into each well. After incubating the ELISA plate at room temperature for an hour, each well was mixture were immunized subcutaneously into a BALB/cCrSlc mouse (Japan SLC Inc., 
$200 \mu \mathrm{g}$ of purified antigen was used for this immunization to a mouse.

After fourth immunization, blood was collected from the heart of the mouse and centrifuged at $3000 \times \mathrm{g}$ for $5 \mathrm{~min}$. Sodium azide was added into this supernatant (serum) to $0.1 \%$, and this mixture was kept at $-30^{\circ} \mathrm{C}$ for further analysis.

\section{Results and discussion}

SAG1 and SRS2 have a signal peptide at its N-terminus and SAG1 also has a transmembrane domain at its C-terminus (Howe et al., 1998; Nishikawa et al., 2002). To express these antigens, sag1 gene lacking the sequences of its native signal peptide and transmembrane domain region was amplified by PCR. Regarding SRS2, full-length srs2 gene fused with bx signal peptide sequence was amplified by PCR. Each PCR product was connected with bx signal peptide sequence and FLAG tag sequence at its $\mathrm{N}$-terminus to secrete each protein into hemolymph of silkworm larvae and make the purification of expressed protein easy.

SAG1 and SRS2 were expressed in hemolymph of silkworm larvae (Fig. 1A).

Hemolymph containing expressed SAG1 and SRS2 had strong reactivity against serum from a N. caninum-infected cow than that from a N. caninum-negative cow (Fig. 1B), suggesting that SAG1, SRS2 are the major immunodominant antigens of N. caninum and candidates for effective vaccines against $N$. caninum-infection. SAG1 was also detected by Western blot using a N. caninum-positive serum (data not shown). SAG1 and SRS2, which have antigenicity against a $N$. caninum-positive serum, 
were purified from hemolymph of silkworm larvae using anti-FLAG M2 antibody agarose. Both SAG1 and SRS2 were purified (Fig. 2A) and its purity was higher than 90\% when purified proteins were analyzed using Experion system (Bio-Rad). Approximately $1.7 \mathrm{mg}$ of SAG1 and $370 \mu \mathrm{g}$ of SRS2 were purified from 10 and 17 silkworm larvae, respectively. Protein yield in silkworm larvae is dependent on protein properties, for example, pI, hydrophobicity and structure etc. (Kato et al., 2010), likely to other protein expression system.

Purified SAG1 or SRS2 was immunized with Freund's complete adjuvant to mice 4 times every two weeks. Their sera were collected, and the production of antibodies against SAG1 or SRS2 was confirmed using indirect ELISA. Absorbance value higher than that in BSA was detected in both proteins, although both sera were diluted by more than 50000-fold (Fig. 2B). It indicates that both proteins induced antibodies against SAG1 and SRS2, respectively, and purified proteins from silkworm larvae have a potential to be used for a vaccine against neosporosis. Up to now, several $N$. caninum-antigens were expressed heterologously. SAG1 and SRS2 that are major immunodominant surface proteins in tachyzoites of $N$. caninum were expressed in $E$. coli as fusion proteins with poly-histidine tag. Purified antigens immunized into mice protected against cerebral N. caninum infection to some extent (Cannas et al., 2003). Several antigens have been expressed in E. coli and cultured insect cells using recombinant baculoviruses and purified antigens have been evaluated as subunit vaccines to cattle. In this study, SAG1 and SRS2 were successfully expressed in 
silkworm larvae using recombinant BmNPV bacmids. SAG1 and SRS2, expressed in

172 hemolymph of silkworm larvae and showed antigenicity to a $N$. caninum-positive

173 serum from cow. Purified SAG1 and SRS2 amounts were 1.7 and $0.37 \mathrm{mg}$ from only

174 10-20 silkworm larvae, respectively. To use recombinant antigen for a vaccine to cattle,

175 large-scale antigen production system is needed inevitably. In the point of the

176 large-scale antigen production, silkworm system is advantageous. This point has a

177 tremendous impact on the production cost of subunit vaccines because any purification

178 steps of recombinant subunit vaccines from hemolymph of silkworm larvae are not

179 needed. BmNPV bacmid silkworm expression system for the production of $N$.

180 caninum-antigens provides its practical application as a recombinant antigen vaccine in

181 the field of livestock industry.

182 Acknowledgements

183 This work was supported by a Grant-in-Aid for Scientific Research (A) Grant

184 No.22248009 from the Ministry of Education, Culture, Sports, Science and Technology.

185 We thank Mr. Junichi Noda of Shizuoka Prefecture Tobu Livestock Disease Diagnostic

186 Center (101 Nitta Kannamicho Tagata-gun, Shizuoka Prefecture, Japan) for providing 187 cattle serum samples.

188 References

189 Baszler, T.V., Shkap, V., Mwangi, W., Davies, C.J., Mathison, B.A., Mazuz, M., 

immune response to inoculation with Neospora caninum surface antigen SRS2 Vaccine Immunol 15, 659-667.

Cannas, A., Naguleswaran, A., Muller, N., Eperon, S., Gottstein, B., Hemphill, A., Parasitology 126, 303-312.

Dubey, J.P., Schares, G., Ortega-Mora, L.M., 2007. Epidemiology and control of neosporosis and Neospora caninum. Clinical microbiology reviews 20, $323-367$. surface- and dense granule-associated Neospora caninum proteins in tachyzoites and bradyzoites. The Journal of parasitology 84, 753-758. 
204
Haldorson, G.J., Stanton, J.B., Mathison, B.A., Suarez, C.E., Baszler, T.V., 2006. Neospora caninum: antibodies directed against tachyzoite surface protein NcSRS2 inhibit parasite attachment and invasion of placental trophoblasts in vitro. Experimental parasitology 112, 172-178.

Hemphill, A., Gottstein, B., 1996. Identification of a major surface protein on Neospora caninum tachyzoites. Parasitology research 82, 497-504.

Howe, D.K., Crawford, A.C., Lindsay, D., Sibley, L.D., 1998. The p29 and p35 immunodominant antigens of Neospora caninum tachyzoites are homologous to the family of surface antigens of Toxoplasma gondii. Infection and immunity 66, 5322-5328.

Kamen, A.A., Aucoin, M.G., Merten, O.W., Alves, P., Hashimoto, Y., Airenne, K., Hu, Y.C., Mezzina, M., van Oers, M.M., 2011. An initiative to manufacture and characterize baculovirus reference material. Journal of invertebrate pathology 107 Suppl, S113-117. 
218 Li, X.H., Wang, D., Zhou, F., Yang, H.J., Bhaskar, R., Hu, J.B., Sun, C.G., Miao, Y.G., 2010. Cloning and expression of a cellulase gene in the silkworm, Bombyx mori by improved Bac-to-Bac/BmNPV baculovirus expression system. Molecular biology reports 37, 3721-3728.

Li, Z., Yi, Y., Yin, X., Zhang, Z., Liu, J., 2008. Expression of foot-and-mouth disease virus capsid proteins in silkworm-baculovirus expression system and its utilization as a subunit vaccine. PloS one 3, e2273. vaccine produced using a silkworm-baculovirus expression system: protective efficacy against two type Asia1 isolates in cattle. Veterinary microbiology 149, caninum NcSRS2 is a transmembrane protein that contains a glycosylphosphatidylinositol anchor in insect cells. Veterinary parasitology 109, 
233

Nishikawa, Y., Xuan, X., Nagasawa, H., Igarashi, I., Fujisaki, K., Otsuka, H., Mikami, T., 2000. Monoclonal antibody inhibition of Neospora caninum tachyzoite invasion into host cells. International journal for parasitology 30, 51-58.

Park, E.Y., Kageshima, A., Kwon, M.S., Kato, T., 2007. Enhanced production of secretory beta1,3-N-acetylglucosaminyltransferase 2 fusion protein into hemolymph of Bombyx mori larvae using recombinant BmNPV bacmid integrated signal sequence. Journal of biotechnology 129, 681-688.

Reichel, M.P., Ellis, J.T., 2006. If control of Neospora caninum infection is technically feasible does it make economic sense? Veterinary parasitology 142, 23-34.

Tsuji, Y., Deo, V.K., Kato, T., Park, E.Y., 2011. Production of Rous sarcoma virus-like particles displaying human transmembrane protein in silkworm larvae and its application to ligand-receptor binding assay. Journal of biotechnology 155 , 185-192.

Usami, A., Suzuki, T., Nagaya, H., Kaki, H., Ishiyama, S., 2010. Silkworm as a host of 
248 Zhou, Y., Chen, H., Li, X., Wang, Y., Chen, K., Zhang, S., Meng, X., Lee, E.Y., Lee,

249 M.Y., 2011. Production of recombinant human DNA polymerase delta in a

$250 \quad$ Bombyx mori bioreactor. PloS one 6, e22224.

251

252 


\section{Figure legends}

254 Fig. 1. (A) Expression of SAG1 and SRS2 in hemolymph of silkworm larvae. Protein

255 expression was analyzed by Western blot using mouse anti-FLAG M2 antibody. (B)

256 Antigenicity of SAG1 and SRS2 expressed in hemolymph of silkworm larvae against a

257 N. caninum-positive serum. Antigenicity of each antigen was analyzed using indirect

258 ELISA as described in Materials and methods. Closed and open bars indicate

259 Neospora-positive and negative sera, respectively.

260 Fig. 2. (A) Purification of SAG1and SRS2 from hemolymph of silkworm larvae using

261 anti-FLAG M2 antibody agarose. Lanes of CBB and WB show SDS-PAGE with

262 Coomassie Brilliant Blue (CBB) staining and Western blot analysis of each purified

263 antigen using mouse anti-FLAG M2 antibody, respectively. (B) Indirect ELISA

264 analysis of serum from mice immunized with purified SAG1 (I) or SRS2 (II). Indirect

265 ELISA method was described in Materials and methods in detail. 
(A)

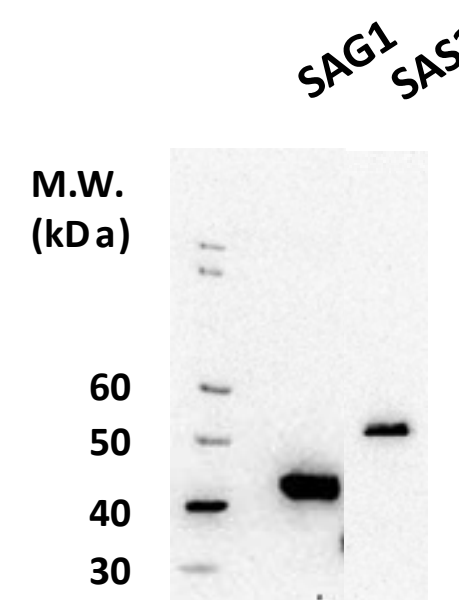

(B)

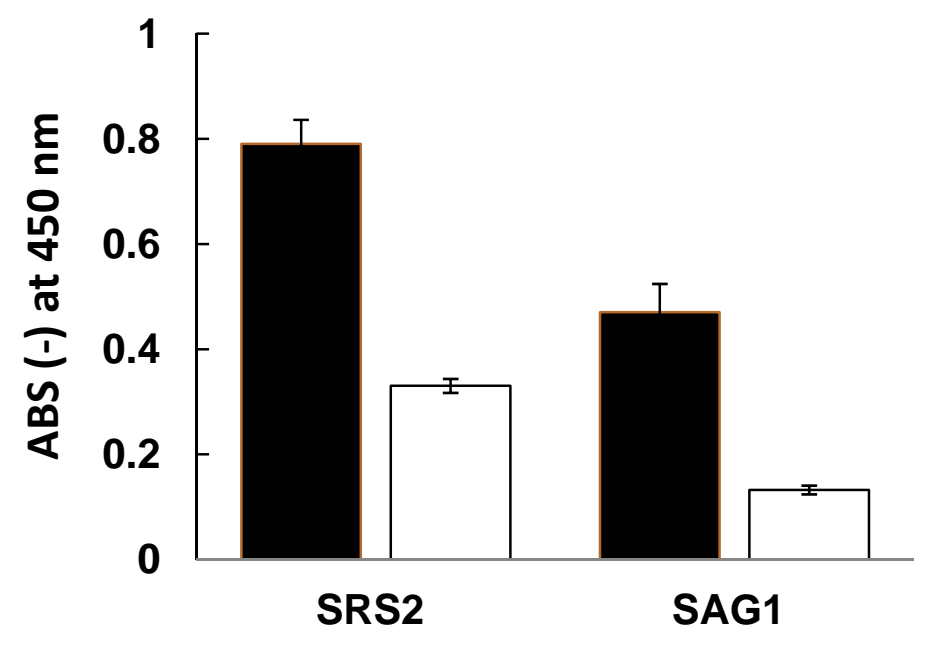


(A)

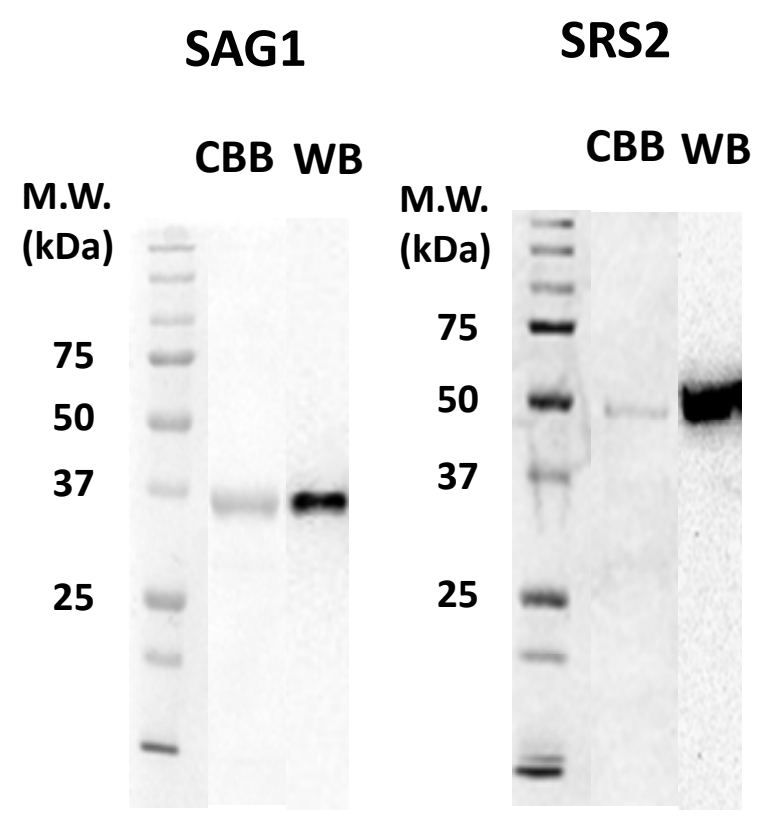

(B)

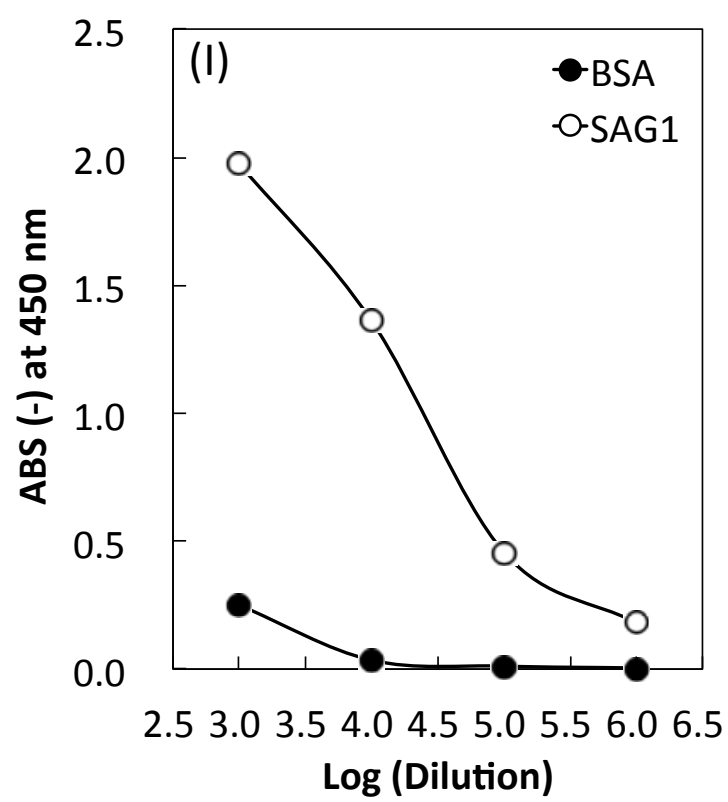

